\title{
Peertechz
}

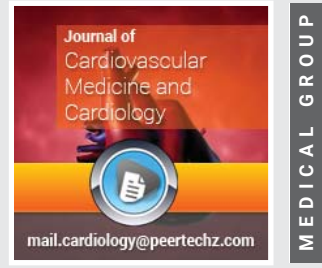

\section{Impaired cardiopulmonary test performance as a marker of early functional impairment in patients with Anderson-Fabry disease}

\author{
Sergio Caravita ${ }^{1,2 *}$, Ilaria Tanini ${ }^{4}$, Lia Crotti ${ }^{1,3}$, Claudia \\ Baratto ${ }^{1}$, Gianfranco Parati ${ }^{1}{ }^{3}$, Francesco Fattirolli ${ }^{5}$, lacopo \\ Olivotto $^{5}$ and Franco Cecchi ${ }^{1,5}$
}

${ }^{1}$ Istituto Auxologico Italiano, IRCCS, Ospedale San Luca, Milano, Italy

${ }^{2}$ Department of Management, Information and Production Engineering, University of Bergamo, Dalmine $(B G)$, Italy

${ }^{3}$ Department of Medicine and Surgery, University of Milano-Bicocca, Milano, Italy ${ }^{4}$ Department of Experimental and Clinical Medicine, University of Florence, Italy ${ }^{5}$ Cardiomyopathy Unit, Careggi University Hospital, Florence, Italy
Received: 25 October, 2021

Accepted: 03 November, 2021

Published: 04 November, 2021

*Corresponding author: Sergio Caravita, MD, Istituto Auxologico Italiano, IRCCS, Ospedale San Luca, Milano, Italy, Tel: +39 02 619112930;

E-mail: s.caravita@auxologico.it

Keywords: Anderson-fabry disease; Exercise; Oxygen consumption; Hypertrophy; Left atrium

Copyright License: (c) 2021 Caravita S, et al. This is an open-access article distributed under the terms of the Creative Commons Attribution License, which permits unrestricted use, distribution, and reproduction in any medium, provided the original author and source are credited.

https://www.peertechzpublications.com

\section{Check for updates}

Anderson-Fabry disease (AFD) is an X-linked lysosomal storage disease characterized by progressive glicosphingolipid accumulation in multiple organs, due to $\alpha$-galactosidase a deficiency [1]. It is considered a rare disease although newborn genetic screening showed non-negligible prevalence ( 1:3.900) [1]. Cardiac manifestations include progressive Left Ventricular (LV) Hypertrophy (LVH), which may be extreme and provoke both reduced stroke volume and dynamic LV outflow tract obstruction [2-6]. Myocardial fibrosis is related to regional and global microvascular dysfunction [1,7-8] and may represent a very early sign of cardiac involvement [8]. LVH and fibrosis may cause symptoms, cardiovascular events, heart failure and death [7].

Enzyme Replacement Therapy (ERT) may be effective to treat AFD, but best results are obtained if started before severe structural cardiac abnormalities develop. In this perspective, the detection of early disease markers is of the utmost importance especially in young women, in whom ERT initiation is debated and often delayed. Cardiopulmonary Exercise Test (CPET) may show even subtle abnormalities in the transport of oxygen from the upper airways to the mitochondria. However, in AFD patients, few studies have focused on exercise test and CPET abnormalities, which are believed to be mainly secondary to LVH [4-6].

With this study, we aimed at describing CPET abnormalities in a cohort of patients with AFD, and their relation with cardiac phenotype. Additionally, we hypothesized that CPET could provide additional information on early cardiac involvement compared to other routinely performed clinical tests, as a potential tool to uncover subclinical AFD manifestations.

We analyzed clinical data from 17 patients (10 females) with genotyped AFD, who underwent thorough clinical assessment, including echocardiography (ECHO), and CPET. ECHO and CPET were conducted according to international standards. In particular, LV mass was calculated using ECHO linear method, as follows: LV mass $=0.8 * 1.04 *\left[(\text { IVS + LVID + PWT })^{3}-\right.$ LVID $\left.^{3}\right]+$ 0.6 , where IVS is interventricular septum, LVID left ventricular internal diameter, and PWT posterior wall thickness, as assessed in two-dimension from a targeted parasternal longaxis view. At CPET, both peak oxygen consumption $\left(\mathrm{VO}_{2}\right)$ $<85 \%$ of predicted values (according to Wasserman-Hansen 
equation) and ratio of minute Ventilation (VE) over carbon dioxide production $\left(\mathrm{VCO}_{2}\right)$ at the anaerobic threshold $\left(\mathrm{VE} / \mathrm{VCO}_{2}\right)$ $>30$ were considered abnormal.

Descriptive data are reported as means \pm standard deviations for continuous variable and as absolute numbers and percentages for categorical variables.

We compared patients with normal and with reduced exercise capacity, as defined by a peak $\mathrm{VO}_{2}>$ or $<85 \%$ of predicted, respectively. Differences between the two groups were assessed for categorical variables with $\chi 2$ test and for continuous variables with unpaired 2 -tailed Student $t$ test. The regression analysis of both LV mass index and left atrial volume index with $\mathrm{VO}_{2}$ was performed using the ordinary least-squares method. An $\alpha$ level of 0.05 was used for all hypothesis tests.

Mean age of the AFD cohort at the time of testing was $49 \pm 23$ years; age at diagnosis was $44 \pm 14$ years. Only one patient had moderate functional limitation (NYHA class III), while 8 patients were in NYHA class II and 8 had no symptoms. All patients exercised to a satisfactory degree, witnessed by a respiratory quotient $\left(\mathrm{VCO}_{2} / \mathrm{VO}_{2}\right)$ at peak exercise of $1.20 \pm 0.14$. Mean peak $\mathrm{VO}_{2}$ for the whole cohort was $23 \pm 5 \mathrm{~mL} / \mathrm{Kg} / \mathrm{min}$ ( $83 \pm 18 \%$ of predicted). However, 10 patients (group A) showed abnormal performance, defined by a peak $\mathrm{VO}_{2}<85 \%$ (range $60-84 \%$ ) (Table 1, Figure 1). They also showed a lower $\mathrm{VO}_{2}$ at anaerobic threshold, as compared with 7 patients with a normal peak $\mathrm{VO}_{2}$ (group B) $\left(41 \pm 11 \%\right.$ vs $63 \pm 14 \%$ of predicted peak $\mathrm{VO}_{2}$ $\mathrm{p}<0.01)$. Other relevant CPET variables did not differ between the two groups. Eight patients (6 from group $A$ and 2 from group $\mathrm{B}, \mathrm{p}=0.092$ ) had a $\mathrm{VE} / \mathrm{VCO}_{2}$ at the anaerobic threshold $>30$. The ratio between $\mathrm{VE} / \mathrm{VCO}_{2}$ was higher in patients of group A than in patients of group B, but the trend was not significant ( $41 \pm 25$ vs $30 \pm 4, p=0.204)$.

There were no significant differences in terms of age, anthropometric variables, gender distribution, haemoglobin and creatinine plasma levels between the patients of group A and $\mathrm{B}$. In group $\mathrm{A}$, only one patient was in permanent atrial fibrillation. Symptoms during exercise, such as dyspnea and chest pain, were similarly distributed among the two groups $(\mathrm{p}=0.606$ and $\mathrm{p}=0.486$ respectively). Patients of group $\mathrm{A}$ were more often on ERT ( $90 \%$ vs $43 \%, p=0.036$ ), had higher prevalence of chronic kidney disease ( $80 \%$ vs $29 \%$, p<0.05) and previous transient ischemic attack or stroke $(40 \%$ vs $0 \%, p=0.056)$. They were also less frequently carriers of the C.644A $>$ G p.Asn215Ser mutation typically causing the cardiac variant of AFD ( $10 \%$ vs $71 \%, \mathrm{p}<0.01)$.

Relevant electrocardiographic and ECHO parameters were similar between the two groups. In particular, 11 patients $(7$ of group A and 4 of group $B, p=0.585$ ) had LVH (septal wall thickness $\geq 13 \mathrm{~mm}$ ). Four subjects (2 per group) had indexed LV mass higher than normal (95-103 g/m2 in 3 females and $125 \mathrm{~g} /$ $\mathrm{m} 2$ in 1 male), despite wall thickness being at the upper limits of normalcy. Two patients (one female per group, respectively aged 25 and 32) had both normal ECG, normal LV wall thickness and indexed mass. However, in the one aged $25, \mathrm{VO}_{2} \max (75 \%$ of predicted) and $\mathrm{VE} / \mathrm{VCO}_{2}=34$ were the only abnormalities suggesting early AFD cardiac involvement.
Table 1: Clinical characteristics of patients with a low (Group A) or a normal (Group B) oxygen consumption at peak exercise.

\begin{tabular}{|c|c|c|c|}
\hline & $\begin{array}{c}\text { GROUP A } \\
(n=10)\end{array}$ & $\begin{array}{c}\text { GROUP B } \\
(n=7)\end{array}$ & $P$ value \\
\hline \multicolumn{4}{|l|}{ General characteristics } \\
\hline Age, years & $46 \pm 14$ & $53 \pm 10$ & 0.251 \\
\hline Females, n (\%) & $5(50)$ & $5(71)$ & 0.377 \\
\hline $\mathrm{BMI}, \mathrm{Kg} / \mathrm{m} 2$ & $22 \pm 2$ & $28 \pm 7$ & 0.079 \\
\hline \multicolumn{4}{|l|}{ Disease characteristics } \\
\hline Age at diagnosis, years & $40 \pm 16$ & $49 \pm 9$ & 0.143 \\
\hline ERT, n (\%) & $9(90)$ & $3(43)$ & 0.036 \\
\hline Age at ERT, years & $44 \pm 17$ & $47 \pm 12$ & 0.769 \\
\hline \multicolumn{4}{|l|}{ Genotype } \\
\hline c.644A>G p. (Asn215Ser), n (\%) & $1(10)$ & $5(71)$ & \\
\hline c.1091_1092del p.(Ser364Leufs*10), n (\%) & $3(30)$ & $0(0)$ & \\
\hline c1A>G p. (Met $1 \mathrm{Val}), \mathrm{n}(\%)$ & $1(10)$ & $1(14)$ & \\
\hline c. $902 \mathrm{G}>$ C p. (Arg301Pro), n (\%) & $2(20)$ & $0(0)$ & \\
\hline c. $131 \mathrm{G}>$ A p. $\left(\operatorname{Trp} 44^{*}\right), \mathrm{n}(\%)$ & $1(10)$ & $0(0)$ & \\
\hline c.896A>G p. (Asp299Gly), n (\%) & $0(0)$ & $1(14)$ & \\
\hline c. $334 C>T$ p. (Arg112Cys), n (\%) & $1(10)$ & $0(0)$ & \\
\hline delACTTex7, n (\%) & $1(10)$ & $0(0)$ & \\
\hline \multicolumn{4}{|l|}{ Symptoms and comorbidities } \\
\hline NYHA class I, n (\%) & $4(40)$ & $4(57)$ & \\
\hline NYHA class II, n (\%) & $5(50)$ & $3(43)$ & 0.606 \\
\hline NYHA class III, n (\%) & $1(10)$ & $0(0)$ & \\
\hline Chest pain, $\mathrm{n}(\%)$ & $6(60)$ & $3(43)$ & 0.486 \\
\hline Atrial fibrillation, n (\%) & $1(10)$ & $0(0)$ & 0.388 \\
\hline Coronary artery disease, $\mathrm{n}(\%)$ & $3(30)$ & $3(43)$ & 0.585 \\
\hline Chronic kidney disease, n (\%) & $8(80)$ & $2(29)$ & 0.034 \\
\hline \multicolumn{4}{|l|}{ Echocardiography } \\
\hline IVS thickness, mm & $14 \pm 4$ & $15 \pm 7$ & 0.622 \\
\hline PW thickness, mm & $13 \pm 4$ & $11 \pm 2$ & 0.135 \\
\hline LV mass index, $\mathrm{g} / \mathrm{m} 2$ & $145 \pm 56$ & $151 \pm 75$ & 0.878 \\
\hline LVH, n (\%) & $8(89)$ & $6(86)$ & 0.849 \\
\hline LV EF, \% & $66 \pm 6$ & $65 \pm 6$ & 0.627 \\
\hline $\mathrm{LAVI}, \mathrm{mL} / \mathrm{m} 2$ & $48 \pm 32$ & $42 \pm 23$ & 0.679 \\
\hline \multicolumn{4}{|l|}{ CPET } \\
\hline Peak workload, watt & $113 \pm 40$ & $125 \pm 26$ & 0.492 \\
\hline Peak HR, \% of predicted & $89 \pm 12$ & $90 \pm 10$ & 0.967 \\
\hline Peak SBP, mmHg & $180 \pm 36$ & $194 \pm 28$ & 0.397 \\
\hline Peak DBP, mmHg & $90 \pm 20$ & $96 \pm 14$ & 0.490 \\
\hline Peak $\mathrm{VO}_{2}, \mathrm{~mL} / \mathrm{Kg} / \mathrm{min}$ & $22 \pm 5$ & $24 \pm 5$ & 0.332 \\
\hline Peak $\mathrm{VO}_{2}, \%$ of predicted & $70 \pm 9$ & $102 \pm 5$ & $<0.001$ \\
\hline
\end{tabular}

$\mathrm{BMI}=$ Body Mass Index; DBP= Diastolic Blood Pressure; EF= Ejection Fraction; $\mathrm{ERT}=$ Enzyme Replacement Therapy; HR= Heart Rate; IVS= Interventricular Septum; LAVI= Left Atrial Volume Index; LV= Left Ventricle; LVH= Left Ventricular Hypertrophy; NYHA = New York Heart Association; PW= Posterior Wall; SBP= Systolic Blood Pressure; $\mathrm{VO}_{2}=$ Oxygen Consumption

There was no correlation between peak $\mathrm{VO}_{2}$ and $\mathrm{LV}$ mass index $\left(\mathrm{R}^{2}=0.034\right)$, while there was an inverse, albeit weak correlation between peak VO2 and LA volume index $\left(\mathrm{R}^{2}=0.150\right)$.

Citation: Caravita S, Tanini I, Crotti L, Baratto C, Parati G, et al. (2021) Impaired cardiopulmonary test performance as a marker of early functional impairment in patients with Anderson-Fabry disease. J Cardiovasc Med Cardiol 8(4): 069-071. DOI: https://dx.doi.org/10.17352/2455-2976.000173 


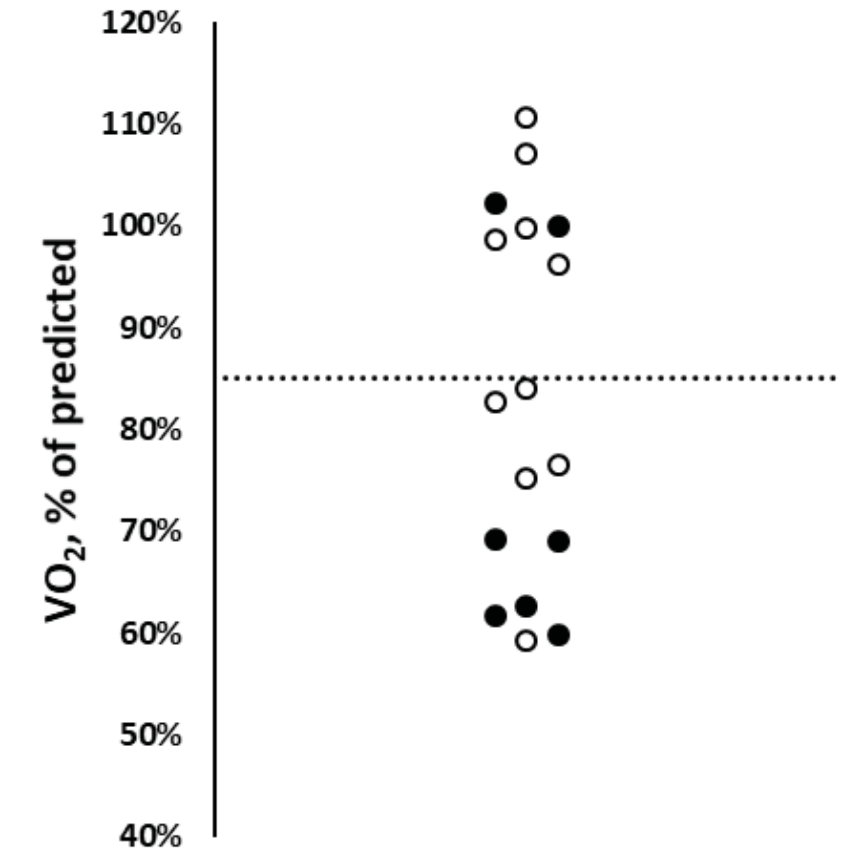

Figure 1: Oxygen consumption at peak exercise in patients with Anderson-Fabry disease. White dots females and black dots males. Dotted line represents the cut-off of $85 \%$ of predicted oxygen consumption at peak exercise, to distinguish normal and abnormal values (above and below the line, respectively). $\mathrm{VO}_{2}=0 x y g e n$ consumption.

Despite our small cohort, motivated by the rarity of AFD, these data suggest that CPET may provide additional information on disease severity and functional limitation also in this specific setting. Indeed, reduced exercise capacity was a frequent finding, irrespectively of the presence and severity of symptoms. It was more common in patients with multisystemic involvement requiring ERT. LVH presence and extent were not clearly associated with exercise limitation, thus suggesting a multifactorial (peripheral and/or central) limitation to exercise in AFD. However, some specific features should be underscored. In particular, the extent of functional impairment in group A (average $\mathrm{VO}_{2} 70 \%$ of predicted) may be hardly explained only on the basis of peripheral/muscular factors. Moreover, it was associated with an anaerobic threshold at the lower limit of normal, somehow reinforcing the possibility of cardiac limitation to exercise. Finally, indexed LA volume, an indirect but rather specific marker of LV diastolic dysfunction and high filling pressure in the left chambers of the heart [1,9], was inversely, albeit weakly, correlated with peak $\mathrm{VO}_{2}$. This link between LA volume and peak $\mathrm{VO}_{2}$ in our cohort of AFD patients raises the suspicion that heart failure with preserved ejection fraction was a likely cause of reduced exercise capacity [10]. Indeed, myocardial fibrosis occurring in AFD, with or without overt $\mathrm{LVH}$, is the anatomical substrate for LV stiffening, eventually accompanied by LA myopathy (mechanical dysfunction and enlargement), which is a hallmark of heart failure with preserved ejection fraction.
It is also important to stress that in a population with subclinical cardiac involvement (i.e. patients with wall thickness still within or at the upper limits of normalcy) CPET was able to identify subtle abnormalities pointing to early stage of AFD-related cardiovascular disease. This might have possible therapeutic implications, e.g. suggesting the utility of ERT initiation.

In conclusion, although CPET may be normal even in patients with severe LVH and LA dilation, impaired exercise performance is common in patients with AFD, and may be detected in the presence of both mild cardiac phenotypes and even in the absence of other detectable abnormalities. CPET may play a role in the early diagnosis of AFD-related functional impairment and provide useful clues for individualized management, including those AFD females with subtle ECHO abnormalities. CPET should be considered in the clinical evaluation of AFD patients.

\section{References}

1. Nagueh SF (2014) Anderson-Fabry disease and other lysosomal storage disorders. Circulation 130: 1081-1090. Link: https://bit.ly/3mE6Z3e

2. Spinelli L, Nicolai E, Acampa W, Imbriaco M, Pisani A, et al. (2008) Cardiac performance during exercise in patients with Fabry's disease. Eur J Clin Invest 38: 910-917. Link: https://bit.ly/3q0jc4k

3. Calcagnino M, O'Mahony C, Coats C, Cardona M, Garcia A, et al. (2011) Exercise-induced left ventricular outflow tract obstruction in symptomatic patients with Anderson-Fabry disease. J Am Coll Cardiol 58: 88-89. Link: https://bit.ly/2ZPZddq

4. Bierer G, Balfe D, Wilcox WR, Mosenifar Z (2006) Improvement in seria cardiopulmonary exercise testing following enzyme replacement therapy in Fabry disease. J Inherit Metab Dis 29: 572-579. Link: https://bit.ly/3mEcrD4

5. Wang RY, Lelis A, Mirocha J, Wilcox WR (2007) Heterozygous Fabry women are not just carriers, but have a significant burden of disease and impaired quality of life. Genet Med 9: 34-45. Link: https://bit.ly/2ZL8Que

6. Lobo T, Morgan J, Bjorksten A, Nicholls K, Grigg L, et al. (2008) Cardiovascular testing in Fabry disease: exercise capacity reduction, chronotropic incompetence and improved anaerobic threshold after enzyme replacement. Intern Med J 38: 407-414. Link: https://bit.ly/3GLYawk

7. Patel MR, Cecchi F, Cizmarik M, Kantola I, Linhart A, et al. (2011) Cardiovascular events in patients with Fabry disease natural history data from the Fabry registry. J Am Coll Cardiol 57: 1093-1099. Link: https://bit.ly/2ZMRSLK

8. Tomberli B, Cecchi F, Sciagrà R, Berti V, Lisi F, et al. (2013) Coronary microvascular dysfunction is an early feature of cardiac involvement in patients with Anderson-Fabry disease. Eur J Heart Fail 15: 1363-1373. Link: https://bit.ly/3k0Gof6

9. Pichette M, Serri K, Pagé M, Di LZ, Bichet DG, et al. (2017) Impaired Left Atrial Function in Fabry Disease: A Longitudinal Speckle-Tracking Echocardiography Study. J Am Soc Echocardiogr 30: 170-179.e2. Link: https://bit.ly/3GHXxDY

10. Baratto C, Caravita S, Soranna D, Faini A, Dewachter C, et al. (2021) Current Limitations of Invasive Exercise Hemodynamics for the Diagnosis of Heart Failure With Preserved Ejection Fraction. Circ Heart Fail 14: e007555. Link: https://bit.ly/3nQ08TD 